\title{
Diálogo con Néstor García Canclini ¿Qué son los imaginarios y cómo actúan en la ciudad?
}

\author{
Entrevista realizada por Alicia Lindón \\ 23 de febrero de 2007, Ciudad de México
}

\begin{abstract}
Néstor García Canclini es Doctor en Filosofía por la Universidad de París y de La Plata, Argentina. Obtuvo la Beca Guggenheim, 1981. Se hizo acreedor a la distinción del Premio de Ensayo Casa de las Américas, 1982, por su libro Las culturas populares en el capitalismo, y al Premio Iberoamericano Book Award de la Latin American Studies Association a su obra Culturas Hibridas.

Entre sus libros se hallan también Consumidores y ciudadanos, La globalización imaginada, Culturas populares en el capitalismo y Diferentes, desiguales y desconectados. Sus temas de investigación actuales son las políticas culturales en los procesos de globalización y las relaciones entre arte contemporáneo y antropología.

Néstor García Canclini es "Profesor Distinguido" en la Universidad Autónoma Metropolitana, campus Iztapalapa, Departamento de Antropología. Asimismo, es "Investigador Nacional de Excelencia”, designado por el Sistema Nacional de Investigadores, de México. El Dr. García Canclini constituye una figura clave del pensamiento latinoamericano sobre Estudios Culturales, y en particular sobre imaginarios urbanos, campo en el cual ha desarrollado "escuela" y ha producido una extensa obra, ampliamente difundida a nivel internacional y en particular en América Latina.
\end{abstract}

\begin{abstract}
Alicia Lindón: Una forma de comenzar a reflexionar sobre los imaginarios urbanos es mediante algunas líneas de entrada lo suficientemente amplias como para no limitar el tema: Una de ellas puede ser la ubicación de los imaginarios urbanos dentro del campo de los estudios urbanos. Una segunda línea podría ser la consideración de los imaginarios urbanos en relación con el pensamiento social, es decir, revisar el tema desde un nivel teórico-epistemológico. Otra línea podría ser lo relativo a lo metodológico, vale decir, los desafíos metodológicos más importantes que asume la investigación social cuando se plantea comprender la ciudad desde los imaginarios urbanos. Otra posibilidad es la de aterrizar el tema en algunas cuestiones concretas -o puntos fuertes- en las que se cristaliza, en particular en América Latina. En estas líneas, entonces, algunas posibles preguntas orientadoras son: ¿Cómo concibe Néstor García Canclini los imaginarios urbanos? ¿Cuál sería su especificidad respecto a los imaginarios sociales en sentido amplio? ¿Cuáles son los temas que se estudian desde la perspectiva de los imaginarios urbanos?........
\end{abstract}

Néstor García Canclini: Una primera cuestión es qué entendemos por imaginario. Según la línea teórica, la actividad o la disciplina en la que nos situemos, las definiciones cambian. A mí me resulta atractiva la definición lacaniana que contrasta lo simbólico y lo real, pero al mismo tiempo no estoy seguro de que sea la más productiva en el trabajo del científico social. En algunos aspectos tal vez lo sea, pero también considero que acota mucho la cuestión del imaginario. Por ello, termino por optar por una concepción que yo llamaría socio-cultural, que coloca lo imaginario en una línea más heterogénea de pensamiento. Esa heterogeneidad resulta de que existen, sin duda, fuentes que se pueden rastrear 
desde la sociología del conocimiento, o desde posiciones marxistas, o también es posible trabajar siguiendo una línea de pensamiento al estilo de la de Castoriadis, o de filósofos como Paul Ricoeur y otros, que han elaborado la cuestión del imaginario como un fenómeno socio-cultural.

En términos muy generales podemos decir que imaginamos lo que no conocemos, o lo que no es, o lo que aún no es. En otras palabras, lo imaginario remite a un campo de imágenes diferenciadas de lo empíricamente observable. Los imaginarios corresponden a elaboraciones simbólicas de lo que observamos o de lo que nos atemoriza o desearíamos que existiera. Una de las tensiones en que se juega el estudio de lo imaginario en el pensamiento actual es en la relación con lo que llamaría totalizaciones y destotalizaciones, considerando que no podemos conocer la totalidad de lo real y que las principales epistemologías contemporáneas desconfían de las visiones totalizadoras. Lo imaginario viene a complementar, a dar un suplemento, a ocupar las fracturas o los huecos de lo que sí podemos conocer. No se ha dejado de hablar de los modos de producción, de totalidades sociales en un sentido amplio, pero actualmente lo hacemos con prudencia y con "temor", sabiendo que no estamos hablando de todo lo que existe. Luego, los estudios transdisciplinarios o interdisciplinarios nos aportan más consciencia sobre lo que cada disciplina recorta y, por lo tanto, sobre la parcialidad de los enunciados y también sobre la dificultad de hablar en nombre de lo humano en general.

Estamos en una situación -en cuanto a la producción de conocimiento- que no es propiamente ni la moderna clásica ni la posmoderna. En la modernidad se aspiraba a un conocimiento científico que pudiera organizar las totalidades sociales y hacer afirmaciones rotundas acerca de cómo funcionaba el mundo, la ciudad o una nación. La posmodernidad tuvo el valor de problematizar los paradigmas o mostrar la relatividad de los modos en que organizábamos el conocimiento y aceptar que podía haber muchas narrativas para un mismo proceso, o para un conjunto de fenómenos. Pero como vemos, por ejemplo, en los estudios sobre cultura, eso también ha llevado a un proceso de fragmentación riesgosa al considerar que podría haber un saber étnico, un saber de género, un saber desde la posición de los grupos subalternos. Esas parcialidades son insuficientes para hablar de lo social. Es cierto que todos distorsionamos desde nuestra perspectiva de análisis, pero es propio del saber científico aspirar a un control de esa parcialidad y buscar un saber lo más universal posible. Entonces, mi posición sería que no podemos afirmar rotundamente que disponemos de un saber, pero tampoco podemos decir que hacemos ciencia, ni siquiera ciencia social, si no problematizamos el punto de vista y las condiciones contextuales, parciales, desde la cuales producimos el conocimiento. En este esfuerzo por producir totalizaciones -no totalidades- que se saben relativas y modificables, lo imaginario y las representaciones que nos hacemos de lo real, aparecen como componentes importantes. Ese sería el núcleo de la problemática epistemológica de los Imaginarios.

También es legítimo hablar, como se hace, de los imaginarios a partir de las prácticas sociales de actores que no tienen la pretensión de construir ciencia ni conocimiento científico. En parte corresponden a la misma dinámica: se trata de ocuparse -con la imaginación- de cómo funciona el mundo y cómo podrían llegar a funcionar los vacíos, los huecos, las insuficiencias de lo que sabemos. Esta tarea la hacen los actores sociales, políticos, los individuos comunes. Conviene distinguir entre los imaginarios producidos por actores comunes, sin pretensiones científicas, de lo que se espera de un científico social, de un investigador. Por eso, digo que estamos en una situación ni propiamente moderna ni posmoderna, en el sentido de que no apostamos por una totalidad dogmática como en cierta modernidad ilustrada se llegó a formular, ni tampoco por una mera fragmentación de lo social, como se pretendió en las narrativas posmodernas.

Si traemos este debate a la cuestión urbana, surgen algunas observaciones e interrogantes. Por una parte, nos encontramos con un objeto de estudio particular -la ciudad- en una perspectiva semejante a lo planteado más arriba: ¿Qué podemos conocer de una ciudad, y especialmente de una gran ciudad? ¿Sólo fragmentos, parcialidades o podemos hacer afirmaciones de un cierto grado de generalidad, que estarán sesgadas por la perspectiva 
del analista o que son relativamente superficiales porque sólo atienden a aspectos socio-económicos, a hechos susceptibles de ser reducidos a estadísticas, a encuestas, al instrumental del conocimiento cuantitativista? En este sentido, nos hallamos en una etapa distinta a la de los estudios urbanos de hace unas décadas, que se sentían más satisfechos con simples descripciones socio-económicas de los desarrollos urbanos. Actualmente, damos mucha importancia a lo cultural, a lo simbólico, a la complejidad y la heterogeneidad de lo social en la ciudad. Es entonces cuando lo imaginario aparece como un componente importantísimo. Una ciudad siempre es heterogénea, entre otras razones, porque hay muchos imaginarios que la habitan. Estos imaginarios no corresponden mecánicamente ni a condiciones de clase, ni al barrio en el que se vive, ni a otras determinaciones objetivables. Aparecen aspectos subjetivos, aunque a mí no me resulta muy convincente reducir lo imaginario a lo subjetivo, porque también la subjetividad está organizada socialmente. Pueden hacerse muchas variaciones desde la perspectiva del sujeto, pero siempre están condicionadas, existe un horizonte de variabilidad que no es enteramente arbitrario.

Confrontar este objeto un poco esquivo que son los imaginarios urbanos- remite a una problemática más que a un objeto rigurosamente acotado. Es la problemática de la tensión entre lo empíricamente observable y los deseos de cambio o las percepciones insuficientes, sesgadas, condicionadas por la comunicación mediática o por otros juegos comunicacionales que, de tanto en tanto, cambian los ejes de los imaginarios. En una temporada puede ser-como ocurrió hace unos años- que el tamaño de la ciudad, la oposición entre el centro y la periferia, el gigantismo amenazante sean esos ejes. Actualmente, los imaginarios van más asociados a la seguridad o la inseguridad, o a la relación entre los nativos y los migrantes. Todas son construcciones histórico-sociales, que por un lado son investigables con instrumentos cuantitativos que alcanzan un cierto grado de rigor. Por otro, requieren también un análisis no sólo explicativo sino interpretativo, con recursos propios de los estudios culturales.

AL. Al inicio comentabas que la perspectiva lacaniana te resulta atractiva, pero que también tiene límites. ¿Cuáles serían esos límites de la perspectiva lacaniana?

NGC. Se han hecho algunos intentos de aplicar el modelo lacaniano, o el modelo psicoanalítico en general, al campo social. La construcción teórica de los grandes psicoanalistas, desde Freud a Lacan así como la de sus seguidores, está concebida para examinar el aparato psíquico individual. Se puede encontrar en los autores de esta línea más sensibles a las resonancias sociales en el individuo, una cierta consideración acerca de la articulación entre lo imaginario, lo simbólico y lo real. Pero básicamente, los instrumentos que nos ofrece el psicoanálisis, incluso los más elaborados, son para analizar individuos. Por otro lado, no me resulta totalmente satisfactoria esa trilogía, esa tríada entre lo real-simbólico-imaginario para analizar fenómenos de cierto espesor social, porque son fenómenos que tienen una complejidad distinta, relacionada con la intersubjetividad, para decirlo en términos más cercanos al psicoanálisis.

AL. Antes planteabas que no sería conveniente reducir los imaginarios a la subjetividad. En este sentido surge una pregunta: Si pensamos la subjetividad como intersubjetividad o como subjetividad socialmente compartida, ¿estaríamos entonces, en el terreno de los imaginarios?

NGC. Hay una serie de nociones que son próximas pero no idénticas: intersubjetividad, interculturalidad, sociabilidad. Intersubjetividad alude a la existencia de sujetos, que se conciben como individuales. No obstante, en tanto existe intersubjetividad, de algún modo se está reconociendo que esos sujetos se constituyen en la interacción social. Aun así, la noción de intersubjetividad no nos permite pasar fácilmente a la noción de sujetos colectivos. Interculturalidad es otra noción que se ha elaborado en años recientes para designar fenómenos de cruces de culturas. En esta perspectiva, lo más estudiado han sido los cruces entre migrantes y nativos, o bien la coexistencia conflictiva de lenguas, de hábitos, de formas de vida y pensamiento, inclusive de estéticas. Podemos encontrar interculturalidad aun dentro de las mismas sociedades, entre conjuntos sociales que hablan la misma lengua o aproximadamente la misma y que, a pesar de ello, tienen diferencias culturales enormes. 
En este momento estoy estudiando formas de extranjería que se producen dentro de una misma sociedad. Por ejemplo, en los estudios comunicacionales se habla de la migración digital para referirse a la experiencia de extranjeridad o la extrañeza que tenemos los adultos cuando necesitamos aprender una nueva lengua para manejar una computadora, acercarnos a Internet, comunicarnos y usar formas digitales de organización de la escritura y del pensamiento. Todos los que hemos aprendido tarde esa nueva lengua tenemos la experiencia de que tropezamos con dificultades semejantes a la de cualquier extranjero. En cambio, cuando le consultamos a nuestro hijo, a un joven de quince años y lo vemos manejarse con gran naturalidad, observamos que se comporta como nativo. Es como una relación entre nativos y extranjeros en el caso de habitantes de una misma sociedad que hablan la misma lengua, pero tiene esta situación complementaria en el acceso a formas de comunicación y de organización del pensamiento, que de pronto resultan extrañas.

Esta relación intercultural tiene mucho interés para la cuestión urbana. Por ejemplo, algo que hemos hallado en los estudios del Grupo de Estudios de Cultura Urbana de la Universidad Autónoma Metropolitana, es que se necesitaba analizar la ciudad de México con dos mapas: Uno es el mapa que podemos llamar real o físico: ¿Cómo está distribuido el espacio urbano?, ¿Quiénes viven en cada lugar? ¿Cuáles son sus hábitos, sus formas de construir, de interactuar, de viajar por la ciudad? $\mathrm{Y}$ otro mapa es el de las comunicaciones masivas, el de las industrias culturales o los medios de comunicación. Este último, en la mayoría de los casos, no es un mapa físicamente situable. Se manifiesta en la deslocalización de las interacciones. Por ejemplo, se ha hecho un lugar común en los estudios sobre la telefonía móvil (celulares), que las etnografías registren en primer lugar, cuando una persona inicia una comunicación, que le pregunta al otro: ¿¿dónde estás? Hay una necesidad de situarlo, y el otro puede contestar lo verdadero o no. No es fácil tener la certeza, podremos buscar referencias en el mapa físico para estar más ciertos de la ubicación, pero persiste la oscilación entre los dos mapas. Las ciudades son conjuntos habitacionales, y conjuntos de viaje, de trabajo y de circulación, físicamente delimitados hasta cierto punto. Por otro lado, o al mismo tiempo, son conjuntos comunicados por redes invisibles, deslocalizadas, con bajo arraigo territorial.

Entonces, los imaginarios aparecen como un componente necesario, constantemente presentado en la interacción social y refiriendo a formas de interacción no objetivables físicamente, o que sólo en forma inmediata pueden aludir a posiciones particulares en la ciudad.

Por lo tanto, los imaginarios se tornan importantes para establecer relaciones de localización de los sujetos, o también su deslocalización o su incierta deslocalización: ¿Desde dónde nos hablan? ¿Quién es el que nos habla? ¿Qué posición ocupa en la ciudad? ¿Cómo se identifica? ¿Cómo conviene interactuar en relación con él? ¿Qué rol vamos a desempeñar de los muchos que actuamos dentro de una ciudad heterogénea?

La idea de la localización incierta me atrae también por la insatisfacción que sentimos con la deslocalización. En una sociedad donde los flujos comunicacionales se han vuelto tan decisivos, hay procesos de deslocalización innegables respecto de lo que estamos acostumbrados a identificar como territorios de pertenencia. Cuando sólo pertenecíamos a una ciudad, o a una nación, la mayoría no viajaba. La mayor parte de los mensajes y los bienes que recibíamos se producían en un entorno más o menos acotado. Pero también sentimos cierto descontento con esa idea de deslocalización, cierta inseguridad, y aparecen constantemente -como decíamos antes- al comienzo de las conversaciones con teléfonos celulares, el deseo de saber dónde está el otro; quién es el otro; por qué nos está hablando a esta hora y en tales términos. La localización, el arraigo, son componentes importantes, aun en una sociedad globalizada. Son localizaciones más inciertas, pero no es indiferente una $\mathrm{u}$ otra.

Aunque se ha relativizado mucho el contexto urbano, ya no sólo son necesarias las discusiones sobre qué es lo que define a una ciudad, sino sobre la manera en que nos situamos respecto de varias ciudades que pueden estar contenidas bajo un mismo nombre: México, Distrito Federal; Santiago de Chile; Buenos Aires; Sao Paulo. Imaginamos las ciudades en zonas conocidas. Atravesamos en una megalópolis ciertas zonas para ir a trabajar, 
a estudiar, a consumir, pero la mayor parte de la ciudad la desconocemos. Fue una de las experiencias que hicimos cuando trabajamos sobre los imaginarios urbanos a partir de los viajes por la ciudad de México. No aparecían visiones totalizadoras de la ciudad, ni siquiera en los sectores con mayor nivel educativo. Cada habitante fragmenta y tiene conjeturas sobre aquello que no ve, que no conoce, o que atraviesa superficialmente. Es una de las maneras de hacer evidente que no hay saberes totalizadores, formas absolutas. Ni el alcalde de la ciudad, ni el mejor especialista en planificación urbana tiene una visión en profundidad del conjunto; pero a la vez llama la atención que en el desarrollo social aparecen simulacros de totalización. El que me atrajo más es el de los helicópteros que en muchas grandes ciudades recorren todas las mañanas la ciudad, ocupados, habitualmente, por un par de policías y algún periodista que transmite por televisión y por radio. El periodista va diciendo dónde hubo un accidente, dónde hay embotellamientos, cómo está el tránsito, nos informa. Pero no sólo da indicaciones más o menos útiles para comportarse en distintas zonas de la ciudad, sino que, en el nivel de los imaginarios se constituye en un reconfigurador de una totalidad que nadie tiene, que se perdió, que nadie logra reconstruir.

Uno puede preguntarse qué consistencia tiene ese imaginario, esa reconstrucción tan bien parcelada y relativamente arbitraria. Esa mirada desde muy arriba hacia fenómenos que están ocurriendo con una complejidad y una intimidad que no se puede captar desde el helicóptero. De todas maneras es interesante destacar que el imaginario se presenta, tiene éxito comunicacional. Estamos alertas a lo que nos dicen en la televisión sobre qué pasó en la ciudad a lo largo del día. La televisión, o a veces Internet, juegan este papel. Entonces, esto está expresando por un lado un deseo de conocimiento y, por otro lado, una carencia que resulta difícil de soportar. Esos dos resortes están en la base de los imaginarios. El imaginario no sólo es representación simbólica de lo que ocurre, sino también es el lugar de elaboración de insatisfacciones, deseos, búsqueda de comunicación con los otros.

AL. Hace tiempo y en otros contextos se ha hablado de la construcción de cada lugar por parte del sujeto que está en el lugar. En ese sentido, se han acuñado conceptos desde distintas disciplinas. Por ejemplo, se puede recordar que los geógrafos humanistas y culturales han hablado del concepto de espacio vivido y otros semejantes. Ahora, entonces, el problema de la particular forma de construir los lugares o fragmentos de la ciudad ya no sería en relación con el lugar en el que estoy, sino en relación con el lugar en el que está el otro, o del cual recibo información. ¿Podríamos pensar más o menos en ese sentido, esta cuestión de los imaginarios urbanos de incierta localización?

NGC. Cabe la pregunta de por qué en los últimos quince o veinte años han aparecido los estudios sobre imaginarios, especialmente los estudios más o menos empíricos, ya que anteriormente en distintas obras, por ejemplo la de Castoriadis, se reflexionaba filosóficamente sobre algunos imaginarios, o en algunos estudios de psicología social se los estudiaba más aterrizados en procesos empíricos. Ahora ocupan un lugar sistemáticamente desarrollado en los estudios urbanos. Hay explicaciones epistemológicas de insatisfacción con el modo en que se ha desarrollado el proceder positivista sobre la ciudad, del cual existen evidencias, por ejemplo, en el fracaso de las planificaciones megaurbanas $y$, también, un acrecentamiento de las experiencias de riesgo o de las dificultades de vivir en la ciudad. Esta preocupación por los imaginarios urbanos va junto con el crecimiento, empíricamente demostrable, de la inseguridad y de la complejidad de las interacciones interculturales por las migraciones, por las transformaciones aceleradas dentro de los propios grupos nativos de distintas generaciones, por los cambios de roles entre hombres y mujeres, entre muchos otros factores de interculturalidad. Es significativo que la preocupación por los imaginarios urbanos aparezca simultáneamente con la irrupción de secciones sobre las ciudades en los periódicos de muchos países. Así como hay una sección de política, otra de asuntos policiales, otra de cultura, otra de economía, existe una sección sobre la ciudad. La ciudad aparece como un objeto de preocupación. Además hay periódicos que se desdoblan en varias ciudades en las que se hacen ediciones especializadas dentro de un mismo país, o para varios países, referidas a ciudades, especialmente de gran tamaño. Existe un reconocimiento 
comunicacional múltiple de la importancia de lo urbano como ámbito organizador de las prácticas sociales y, a la vez, como un lugar incierto, intranquilizante. Nos resulta más fácil hablar de la ciudad que hablar de la Nación, pero en rigor no vemos menos compleja la ciudad que la Nación. La ciudad nos resulta más próxima, está más al alcance de nuestra mano, a veces tenemos más información. La ciudad tiene una heterogeneidad, a veces, menor que la Nación, pero a veces, ciertas megalópolis son condensaciones del conjunto de etnias, de grupos, de regiones que una Nación contiene. Entonces puede ser tan compleja la ciudad como una Nación.

AL. La expresión localización incierta tiene muchos aspectos para reflexionar. Por ejemplo, en esencia la palabra localización viene de una perspectiva geométrica, positivista, euclidiana, la ubicación de un punto concreto. Pero, al mismo tiempo al llevar el adjetivo de incierta justamente pierde esto. Entonces la localización incierta ¿podría ser algo así como pensar la ciudad desde imaginarios urbanos inciertamente localizados?, ¿podría expresar el reconocimiento de la tensión entre lo que se fija en un territorio y al mismo tiempo se desprende?

NGC. También podríamos emplear otros adjetivos en vez de "incierta". Por ejemplo, se podría hablar de localizaciones con significados diversos. Estoy pensando aquí la localización incierta en oposición a la noción de "no lugar", que nos sedujo en algún momento, cuando Marc Augé la formuló. Luego, comenzamos a ver que un aeropuerto podía ser un no-lugar para el que iba a tomar el avión, pero para quien trabaja en el aeropuerto todos los días es un lugar. Y esto ocurre con casi cualquier espacio urbano, puede ser lugar para uno, no-lugar para otros y un lugar a medias para mucha gente. Entonces, la oposición de la ciudad como lo local frente a lo global es muy relativa. ¿Qué parte de la ciudad? ¿Para quiénes? ¿Cómo la usan? ¿Cómo nos apropiamos del espacio urbano? De muchas maneras, siempre desiguales, asimétricas, parciales. En síntesis, no hay localizaciones absolutas. Se podría agregar que ciertos procesos importantes en ciudades grandes y medianas, están cambiando constantemente, o pueden modificarse en un mismo día. Los vendedores ambulantes son uno de los ejemplos que lo dicen más elocuentemente: se localizan, tienen un lugar al que suelen ir todos los días, un lugar en el que conocen más o menos con quién interactuar, quiénes les van a comprar, qué mercancía es interesante allí. Pero llega la policía $\mathrm{y}$ tienen que salir corriendo. Llegan los inspectores y tienen que negociar con ellos. Los pueden llevar presos. Hay muchos lugares inciertos, no todos tenemos la fragilidad de los ambulantes, pero todos sentimos que pueden sucedernos hechos imprevistos en la ciudad y en cada lugar.

AL. Habíamos planteado también una entrada más metodológica al tema de los imaginarios urbanos, que se podría enfocar en estos términos: Si los imaginarios urbanos constituyen una nueva aproximación al estudio de la ciudad que trata de superar las limitaciones que por mucho tiempo tuvieron los estudios urbanos dedicados a describir los lugares, al recuento de lo material que en ellos había, también se debería reconocer que es una aproximación que conlleva numerosas dificultades y desafíos metodológicos. Es frecuente que la investigación urbana en América Latina, penetre rápidamente en estas nuevas perspectivas que parecen abrir muchos planos antes ocultos. Pero en el momento de definir las herramientas también es usual seguir acudiendo a las herramientas que hemos usado desde otras miradas. Ante esto, un interrogante podría ser ¿qué implicaría actuar así? Por ejemplo, el uso del cuestionario tan legitimado en las ciencias sociales en general, $\mathrm{y}$ en los estudios urbanos en particular. Esto nos lleva a preguntarnos: ${ }_{i}$ Es una buena estrategia recurrir al cuestionario de encuesta para estudiar los imaginarios urbanos?

NGC. En relación con el uso de métodos cuantitativos y cualitativos considero que la encuesta es indispensable, así como los otros recursos cuantitativos más objetivables: los censos, las estadísticas, los datos duros. Gran parte de la sociología urbana se sigue haciendo con esos recursos y se ignoran las representaciones, los procesos culturales, y por lo tanto, los imaginarios. Ocurre menos el camino inverso, aunque también se ve. En otras palabras, quienes estudiamos los procesos culturales no disponemos siempre de suficientes recursos cuantitativos, objetivables, para controlar lo que afirmamos sobre la ciudad. Sin embargo, es más 
frecuente encontrar en estudios sobre las culturas urbanas referencias a las bases socioeconómicas, arquitectónicas, urbanísticas, referencias duras, que a la inversa. A mí me resulta indispensable trabajar en las dos dimensiones. Para ponerlo en términos un poco extremos, considero que históricamente hemos tenido frente a nosotros extremos de los dos lados: los planificadores urbanos basados en la economía urbana, el estudio del desarrollo físico-espacial de la ciudad, han tomado decisiones acerca de qué se puede construir, por dónde debe trazarse el transporte, si se debe impulsar el Metro o el Metrobus, cuánto se puede tolerar el transporte individual o cuándo estimularlo. En general se decide según criterios cuantitativos y de una pretendida objetividad, sin tomar en cuenta la experiencia vivida de los que viajan, de los que trabajan, de los que habitan la ciudad.

También se debe reconocer el riesgo opuesto, frecuente entre antropólogos y psicólogos sociales: sobreestimar la dimensión imaginaria, cultural o subjetiva de la experiencia. Esta tendencia se ha acentuado con la influencia de los estudios culturales de origen estadounidense, que son muy textualizantes de lo social, tienden a sobredimensionar el papel de los discursos en las interacciones sociales. Eso conduce a otros tipos de extremos y fantasías, por ejemplo a creer que lo que dicen los actores es cierto porque ellos así lo creen. Algunos buenos estudios sobre los imaginarios urbanos han mostrado, por ejemplo, que ante la pregunta ¿cuántos habitantes tiene la ciudad de Bogotá?, se respondía más o menos aproximadamente los millones de habitantes que realmente había en la ciudad. Sin embargo, cuando se les preguntaba: ¿Y cuánto cree que va a haber en 2020? La respuesta era cuarenta millones. Es importante tomar en dos sentidos esa respuesta: Por un lado, como falsa respecto a lo que es predecible con el desarrollo urbano. Para ello hay que confrontarla con los datos duros de la demografía y de la capacidad de crecimiento de un cierto espacio. Pero por otro lado, esta respuesta tiene su importancia porque muestra que estos sujetos están expresando una visión paranoica, amenazante, y que eso está expresando la opinión de muchos otros.

El tema del gigantismo urbano lo hemos encontrado detrás de muchos fenómenos complejos, como la valoración del lugar de los migrantes y su influencia en la vida de la ciudad. En Europa se han hecho estudios importantes en ese sentido. Hay pocas ciudades europeas que tengan más de un diez o un quince por ciento de migrantes, sin embargo, la experiencia de la población cuando le preguntan sobre el papel de los migrantes o les piden estimaciones sobre su peso demográfico no corresponde a esos porcentajes. Por un lado, esto nos muestra la importancia de poner en relación hechos objetivamente observables y cuantificables con los imaginarios sobre estos hechos, porque ambas dimensiones forman parte de las interacciones efectivas.

En esto se puede considerar -como decíamos antes- un lado epistemológico y metodológico, y otro de tipo político. Veamos primero el epistemológico. Necesitamos recurrir a encuestas, censos, estadísticas; y también necesitamos historias de vida, entrevistas en profundidad, observaciones etnográficas detenidas de larga duración en espacios acotados. En gran medida todavía seguimos orientados disciplinariamente. Los sociólogos hacen lo primero. Los antropólogos lo segundo. Pero cada vez vemos más corrimientos por fuera de las disciplinas. Hay sociólogos y comunicólogos que también se sientan con la gente a viajar, a ver televisión en la casa, observan prolongadamente comportamientos particulares, individuales. $\mathrm{Y}$ algunos antropólogos intentamos trascender el barrio, la colonia, para decir algo sobre el conjunto de la ciudad. Descubrimos en estos procesos que, cuando sólo hablamos de lo macro y desconocemos la heterogeneidad, la variedad de experiencias, gran parte de lo que afirmamos es falso o incorrecto. Pero también ocurre que, cuando extrapolamos del estudio en profundidad de un barrio lo que le sucede a esa misma población del barrio en relación con el conjunto de la ciudad, resulta falso. La gente que vive en una zona de la ciudad atraviesa muchos otros lugares para trabajar, para educarse, para consumir, y tiene otro tipo de experiencias, de interacciones que pasan a formar parte de su vida cotidiana.

Un problema es cómo reelaborar las técnicas cuantitativas y cualitativas. Hasta qué punto una encuesta puede incluir no sólo opciones múltiples dentro de un estándar precodificado, sino algunas 
preguntas abiertas que den posibilidad de que la forma de plantear la pregunta sea desafiada por el entrevistado. Y lo mismo a la inversa: cómo hacer entrevistas individuales de modo que podamos reconstruir relaciones grupales, colectivas.

Es importante someter unas técnicas y otras, y los resultados, la información que obtenemos, a un análisis macro del desarrollo socio-comunicacional de las ciudades. Un ejemplo que hallé en dos encuestas con las que trabajé el año pasado: una de ellas es la Encuesta Nacional de la Juventud, que se hizo en México a nivel nacional, a través del Instituto Nacional de Juventud. La otra fue la encuesta sobre los hábitos de lectura en México, que también abarcó todo el país. Al poner las dos encuestas en relación, surgió la evidencia: en la encuesta sobre lectura se había preguntado lo que habitualmente se averigua en estas encuestas: si leen libros y revistas, dónde los compran, cómo los leen, qué preferencias tienen. Como un anexo se había interrogado sobre equipamiento cultural hogareño. Entonces aparecieron las computadoras, el acceso a Internet, pero no se preguntó qué se leía en Internet. Se partía del presupuesto, no explicitado en la encuesta, de que leer es leer en papel, leer lo que está escrito en papel. Cuando presentamos la encuesta públicamente, comenté esta observación acerca del modo en que se había interrogado, y que seguramente habría un índice de lectura mucho mayor y hábitos distintos de los que la encuesta había previsto, especialmente en los jóvenes que tienen mayor acceso a las nuevas tecnologías. A mi lado estaba uno de los principales editores de México, René Solís, que tomó la preocupación y agregó una historia personal: dijo que él es de un pueblo de Sinaloa de diez mil habitantes, donde no había diarios, no llegaban periódicos regionales ni nacionales, no había bibliotecas; había que hacer más de cuarenta kilómetros para comprar libros y diarios, pero en ese pueblo de diez mil habitantes había cuatro cibercafés.

Esto muestra que tiene sentido modificar el modo de interrogar sobre qué significa leer en relación con esta recomposición de las comunicaciones, de la oferta cultural y de los hábitos de la población en ciudades grandes y pequeñas.
Por supuesto, una de las consecuencias de esta recomposición de las comunicaciones es que se aproximan los pobladores de ciudades de diez mil habitantes con los que vivimos en ciudades de diez o veinte millones, por lo menos en algunos hábitos culturales. La relación con el papel, con la biblioteca, será distinta, pero es posible que unos y otros accedan a información semejante sobre el país y sobre el mundo; puedan ver películas, unos en pantalla grande, otros en pantalla chica. Hay muchos más puntos de acercamiento, de convergencia.

Esto tiene algunas consecuencias también sobre la metodología de investigación. Nos planteamos una encuesta para una gran ciudad, pero si estudiamos una población de tres mil habitantes puede no resultar tan adecuado hacer una encuesta. Quizá sea mejor hacer observación etnográfica y entrevistas.

Las distancias por tamaño de población no son traducibles en hábitos culturales tan distintos ahora como en el pasado y, por supuesto, ello tiene efectos sobre las políticas. Por lo general, como decíamos, las políticas las hacen los planificadores urbanos, o los políticos, o los gestores sociales, urbanos y culturales, a partir de información macro obtenida con encuestas, con grandes recursos de investigación cuantitativa. Casi nunca consideran los imaginarios urbanos o las representaciones culturales de los procesos. Sin embargo hay unos pocos casos, como el de Antanas Mockus en Bogotá, que se propuso modificar los hábitos de la población, reducir la violencia en las interacciones cotidianas, no la violencia guerrillera o terrorista, sino el enfrentamiento entre los peatones y los automovilistas, con una serie de intervenciones simbólicas: payasos en las esquinas que jugaban humorísticamente con las situaciones, que trataban de "educar" a la población. Efectivamente, Antanas Mockus, filósofo y matemático ${ }^{1}$, tuvo

\footnotetext{
Antanas Mockus Šivickas es un político y filósofo colombiano. Magister en Filosofía (Universidad Nacional de Colombia), Licenciado en Filosofía y Matemáticas (Universidad de Dijòn - Francia), Doctor Honoris Causa (Universidad de París XIII, Francia) y de la Universidad Nacional de Colombia. Fue alcalde de Bogotá en dos ocasiones (1995-1997 y 2001-2005). Mockus ha trabajado académicamente tanto en el área de las matemáticas como en la de la filosofía, convirtiéndose en profesor e investigador de la Universidad Nacio-
} 
una sensibilidad fina hacia estos fenómenos. Sin embargo, es discutible cuánto se pueden modificar los comportamientos a través de lo simbólico. El grado de congestionamiento urbano que ha propiciado un uso indiscriminando y excesivo del automóvil individual, no se puede modificar sólo a través de lo simbólico, ni sólo mediante cambios estructurales en el espacio físico. Existe una correspondencia entre la necesidad de utilizar procedimientos cuantitativos y cualitativos en la investigación, que capten las distintas densidades de las interacciones urbanas y, al mismo tiempo, en el nivel de las políticas proceder con relación a las dos dimensiones, los comportamientos y lo simbólico.

AL. ¿Los instrumentos cuantitativos nos permitirían captar los imaginarios o fragmentos de imaginarios, o simplemente nos permitirían definir una serie de coordenadas del sujeto?

NGC. Todo depende de cómo se formulen las preguntas y cómo se correlacionen los datos duros con los datos blandos. Esto tiene que ver, por ejemplo, con la manera en que se han investigado imaginarios en distintas ciudades y los productos que han aparecido en los últimos años. Voy a recurrir a dos ejemplos: uno es del nuestra investigación en la ciudad de México a partir de los viajes por la ciudad. Usamos dos instrumentos: fotos y escenas de películas. Fotos sobre viajes en la ciudad de distintas épocas desde mediados del siglo XX hasta 1995, que fue cuando hicimos la investigación. Las escenas eran de películas mexicanas que mostraban trayectorias urbanas, viajes por la ciudad, fotos de individuos, de medios de transporte, de distintas épocas, y experiencias que ocurrían. Hicimos una investigación sobre el material fotográfico y cinematográfico para recoger una gran variedad de imágenes en el caso de la fotografía y de relatos visuales en el caso del cine. Formamos grupos de gente que viaja intensamente por la ciudad, grupos focales de ocho a diez personas. Integramos un grupo con repartidores de alimentos, otro con madres que llevan los niños a la escuela, otro con policías de tránsito, otros

nal de Colombia desde 1975 hasta la fecha. Fue vicerrector (1988 a 1991) y luego rector de la Universidad Nacional de Colombia entre 1991 y 1993. de estudiantes que vivían lejos de la universidad, en fin... Buscamos una cierta heterogeneidad sin pretensión de exhaustividad, pero, para recoger experiencias diversas y ver cómo reaccionaban. La técnica consistía en mostrarles cincuenta fotos sobre una mesa, que habían sido tomadas en distintas épocas entre 1950 y 1995 . Algunas fueron tomadas por extranjeros, la mayoría por fotógrafos mexicanos. Le solicitábamos a cada grupo que eligiera las diez fotos que le resultaban más representativas acerca de la forma en que se viajaba por la ciudad. En ese momento se iniciaba una discusión acerca de qué fotos, y cómo se viajaba antes y cómo se viajaba ahora, por qué hay tantas dificultades; aparecían bocetos de explicaciones. Se grabó todo ese material, se hacían muy pocas preguntas. Por lo general, en una hora de análisis de las fotografías la gente se entusiasmaba y le imprimía su propia dinámica al trabajo. Al final, les preguntábamos qué fotos faltan.

Después, en una segunda hora de trabajo colectivo mostrábamos durante veinte minutos la edición de escenas de varias películas, también de distintas décadas, donde aparecían viajes por la ciudad. Hacíamos el mismo ejercicio, que seleccionaran las que consideraban más representativas.

Surgió algo semejante en todos los grupos, de distinto nivel, de diferentes ocupaciones y edades: las fotos disparaban muchos más comentarios, eran más estimulantes. En cambio, las escenas de narración cinematográfica eran más débiles en cuanto a lo que provocaban. Nos preguntamos por qué. En realidad, esto surgió después del trabajo con la gente, cuando ya teníamos el material, y no podíamos volver a trabajar con los mismos grupos. Pero la hipótesis que me resultó más atractiva tiene que ver con una cuestión relativamente formal: la fotografía da una sola imagen que puede ser interpretada de muchas maneras. El relato cinematográfico da muchas imágenes, pero encadenadas por una narración que establece un sentido bastante preciso de los hechos. Por lo tanto, el relato cinematográfico permitiría imaginar menos sobre aquello que vemos. El cine está induciendo una cierta lectura de los procesos.

Otra evidencia que apareció en la investigación: nosotros ya habíamos hecho encuestas y 
entrevistas sobre los viajes por la ciudad, teníamos una información contextual, incluso estadística, acerca de cuánta gente viajaba en el Metro por día, cuántos lo hacían en otros medios de transporte, cuántos lo hacían en automóvil. Sin duda, la fotografía aparecía como una pregunta más abierta que la pregunta verbal y, a su vez, la fotografía fue capaz de disparar respuestas diversas que lo que permitió la narración cinematográfica que condicionaba más la respuesta. Son algunas evidencias de la fecundidad de unas y otras técnicas; de unos y otros recursos de provocación de la información.

El otro comentario metodológico que me surge de las encuestas utilizadas para captar información sobre aspectos cualitativos, como por ejemplo cuáles son los colores, los sabores atribuidos a las calles de una ciudad o qué es lo que se considera como el centro de una ciudad. Esas preguntas tienen dos aspectos que me han llamado la atención. Uno es que, en general, la búsqueda indirecta a través de referencias afectivas expresa sensaciones, movimiento de la afectividad, pero da poca información sobre la conceptualización de lo urbano. En este sentido, no considero muy fecunda la utilización de encuestas para explorar aspectos extremadamente cualitativos y estéticos, como serían los del color o el sabor. El otro problema que surge en el estudio comparativo de muchas ciudades, como el que coordinó Armando Silva, es que aparece una diferencia en cuanto a la capacitación explicativa-interpretativa de los autores de los diferentes libros. Por ejemplo, el libro de Armando Silva sobre Bogotá, sobre los imaginarios urbanos en Bogotá, es muy sutil, muy sofisticado, tanto para la construcción del objeto de estudio, como para la interpretación del material. No es la misma situación la que se expresa en los otros casos, de otras ciudades. El libro sobre Barcelona parece una descripción ni periodística ni turística, pero claramente no es científico-social. Es otra aproximación. En otras ciudades, el libro sobre Santiago de Chile, por ejemplo, es mucho más elaborado, más complejo porque está hecho por personas que tienen un conocimiento de teoría social y cultural sólido. Entonces, las preguntas de partida y la organización de la información hacen interactuar todos estos niveles cualitativos y cuantitativos; los discursivos y no discursivos.
Hay un aspecto más que me parece percibir en esa serie, y en otros trabajos sobre imaginarios urbanos: que la experiencia etnográfica prolongada, que puede estar basada en ser un habitante de la ciudad o en hacer periodos prolongados de trabajo de campo da una densidad que no se puede obtener con una encuesta, ni siquiera con una encuesta que busque lo cualitativo.

AL. Entonces ¿podríamos reconocer que lo cualitativo tiene una centralidad metodológica enorme para los imaginarios urbanos? Aun cuando ello no niegue la importancia de recurrir a las dos perspectivas. En cuanto a estos estudios comparativos en términos de América Latina, evidentemente hay una diferencia sustancial en cuanto a la perspectiva de los autores, pero también me pregunto si la diferencia entre las ciudades mismas no es acaso un problema para la comparación.

NGC. Por supuesto. Tanto la diferencia en el tamaño de las ciudades o las diferencias en las experiencias históricas entre unas ciudades y otras, así como los distintos modos de organizar el espacio, las hacen distintas. Esto tiene consecuencias sobre afirmaciones modernas o posmodernas respecto a lo urbano, cuando se comparan ciudades europeas y latinoamericanas. Así, por ejemplo, en ciudades con larga organización que, como las europeas, muy estructuradas, con una cuadrícula, con un tipo estable de interacciones, una distribución de la población en el espacio muy establecida y donde el ritmo de crecimiento no fue tan rápido, la exaltación de la fragmentación urbana tiene implicaciones distintas que hacerlo en las ciudades latinoamericanas. En esas ciudades europeas exaltar la fragmentación es quizá propiciar la democratización, la descentralización, el análisis particular de las distintas experiencias urbanas, la consideración específica de actores muy distintos. En América Latina, la exaltación de la fragmentación es la consagración del desorden y es una forma de prohibirse pensar la necesidad de la planificación macro que, aunque sea difícil, sigue siendo urgente.

AL.: De todo esto me surge una inquietud: ¿si finalmente los imaginarios urbanos, como perspectiva para estudiar la ciudad, son realmente una mirada novedosa, o si, acaso no estaremos 
llamando con otro nombre a perspectivas que anteriormente ya las teníamos, las planteábamos, se utilizaban.

NGC. Es un problema, no sólo de lo urbano sino en general de los estudios sobre la cultura o sobre los procesos simbólicos: la forma de nombrarlos suele implicar una delimitación, una caracterización del objeto de estudio, que tiene consecuencias o implicaciones para la investigación. A pesar de toda la discusión y la dificultad que actualmente tenemos para definir la cultura, ésta sigue siendo la expresión más abarcadora, sobre todo si hablamos de procesos culturales, no de cultura sustantiva, sino de lo cultural, como dice Arjun Appadurai, de los procesos culturales. Así nos remitimos a un universo de conocimientos y de caracterización de los procesos más específicos, más abarcador aun que al hablar de imaginarios.

No obstante, es pertinente hablar de imaginarios, pero me parece que es una problemática dependiente de cuestiones culturales más amplias. Por ejemplo, con la noción de procesos culturales podemos analizar imaginarios, pero encontramos también recursos en las teorías socio-antropológicas de la cultura para estudiar aspectos físicos o institucionales de la oferta cultural, de la distribución en el espacio urbano, de las desigualdades que se crean cuando los teatros están todos concentrados en una zona o las librerías en otra, o las universidades en otras, y las fábricas y los lugares de baile en otras. Existen aspectos de los procesos culturales que tienen una base institucional importante, que tienen un sustento socio-económico y demográfico objetivable. Las teorías socio-antropológicas de la cultura dan una caracterización e integran un conjunto de recursos metodológicos como para trabajar más integralmente los procesos, que si nos limitamos al exclusivo análisis de lo simbólico con el consecuente riesgo de textualización, o de considerar sólo las representaciones imaginarias sin los soportes.

AL. Entonces, ¿los imaginarios se pueden entender sobre una perspectiva antropológica más amplia, y por lo mismo no deberíamos hacer sinónimos imaginarios urbanos y cultura urbana? Si lo vemos así, tomaría mayor sentido estudiar la ciudad desde los imaginarios urbanos porque, así como lo podríamos sustentar con teorías antropológicas más amplias, también lo podríamos sustentar con teorías sociológicas, teorías de geografía humana. En síntesis: ¿podríamos pensar a los imaginarios urbanos como tributarios de una cuenca amplia de transdisciplinariedad?

NGC. La noción de imaginarios remite más a aspectos donde lo real, lo objetivo, lo observable es menos significativo. Reconoce más fuertemente el carácter imaginado. Estamos frente a un proceso de fundamentación y reconstrucción incesante del objeto.

AL. Esto tiene mucho sentido para los estudios urbanos porque finalmente, aunque algunas disciplinas han contribuido fuertemente a ellos, siempre han sido transdisciplinarios, se han desarrollado entre disciplinas, atravesando disciplinas, en el diálogo entre disciplinas. Así, me pregunto si los imaginarios urbanos podrían ser una nueva etapa de los estudios urbanos, en la que se relativiza el peso fuerte de lo material.

NGC. Es una necesidad en cualquier objeto de análisis de las ciencias sociales. La época de los estudios de los modos de producción, como fueron los económicos, o la globalización como un proceso solo económico y tecnológico, se mostró muy insuficiente. Quien no considere los aspectos imaginarios de la globalización entiende poco. 